Brit. J. prev. soc. Med. (1975), 29, 111-115

\title{
Potato avoidance during pregnancy in women with a previous infant with either anencephaly and/or spina bifida
}

\author{
N. C. NEVIN AND J. D. MERRETT \\ Department of Medical Statistics, The Queen's University of Belfast, Northern Ireland
}

\begin{abstract}
Nevin, N. C. and Merrett, J. D. (1975). British Journal of Preventive and Social Medicine, 29, 111-115. Potato avoidance during pregnancy in women with a previous infant with either anencephaly and/or spina bifida. This investigation is a direct attempt to test Renwick's (1972) hypothesis that $95 \%$ of anencephaly and spina bifida (ASB) is preventable by the avoidance of potatoes during pregnancy. Although the numbers involved in the study are small, the investigation fails to support the concept that short-term avoidance of potatoes before conception and throughout pregnancy in women who have had a previous ASB infant reduces the recurrence risk. In the potato-free group, of 23 pregnancies which went to term two infants had ASB (8.7\%); whereas in the non-potato-free group, of 56 which went to term two infants had ASB (3.6\%). The recurrence risk in both groups was about $5 \%$. The incidence of ASB in the groups shows no significant difference $(P=0.58)$ and in the potato-free group was not reduced by $95 \%$ as postulated by Renwick.
\end{abstract}

Anencephaly and spina bifida (ASB) are important human malformations. In Northern Ireland the frequency per 1000 total births is $4 \cdot 2$ for anencephaly and 4.5 for spina bifida (Elwood and Nevin, 1973). As with other common malformations, the aetiology of ASB appears to be multi-factorial (Carter, Laurence, and David, 1967) with a significant genetic component and a substantial environmental component. The genetic component is probably polygenic but the mechanism by which it acts is unknown. The environmental component is also unknown but evidence for such a component is overwhelming (Leck, 1974). This evidence includes a marked geographical gradient of these malformations in the United Kingdom (the incidence increasing from the south and east to the north and west), a social class gradient, seasonal differences, long-term secular trends, and maternal age and birth rank variations. There appears to be no association of ASB with maternal infection, but recently several authors have suggested a correlation of the incidence of ASB with various dietary factors (Knox, 1972; Renwick, 1972; Fedrick, 1974).
In 1972 Renwick proposed that specific but unidentified factor(s) present in potato tubers, possibly a teratogenic antibiotic induced by the potato blight fungus Phytophthora infestans, might be the causal factor(s) in ASB, and claimed that $95 \%$ of all ASB could be prevented by avoidance of potatoes (not merely blighted potatoes) during early pregnancy. Some experimental support for the potato theory has been provided by Poswillo, Sopher, and Mitchell (1972), who found midline malformations of the cranium in four of 11 embryos of female marmosets fed with blighted potatoes. Supplementary experiments, however, failed to reproduce these defects (Poswillo, et al., 1973).

Some case reports indicate that short-term potato avoidance in mothers with a previous ASB infant fails to prevent recurrence of the malformation (Lorber, Stewart, and Ward, 1973; Lorber, 1974). However, the only effective way of testing his hypothesis is by way of a prospective potato avoidance trial (Renwick, 1973). The present investigation is the first published report of a trial of potato avoidance in women with at least one infant with ASB. 


\section{MATERIAL}

From July 1972 until October 1973 all couples with an infant with either anencephaly and/or spina bifida attending the Genetic Counselling Clinics at the Royal Belfast Hospital for Sick Children and the Royal Victoria Hospital were advised to avoid eating potatoes as soon as they decided on another pregnancy. Each mother was given a list of common proprietary foods which contained potato. Of these mothers, 88 were again seen at the Genetic Counselling Clinic when six to eight weeks pregnant. Questioning revealed that 27 women had not eaten, handled, or indeed had potatoes or potato-containing foods in their homes from their first consultation at the Genetic Counselling Clinic and throughout the pregnancy. These women constituted the potato-free group. The remaining 61 women who had not made any attempt to avoid or limit potatoes in their diet constituted the non-potato-free group. For each member of the two groups, the following information was recorded: maternal age, social class, religion, parity, outcome of previous pregnancies, the number of infants with anencephaly and/or spina bifida, and the outcome of the current pregnancy.

TABLE I

AGE DISTRIBUTION, SOCIAL CLASS, AND RELIGION, IN POTATO-FREE AND NON-POTATO-FREE GROUPS

\begin{tabular}{|c|c|c|c|c|}
\hline & \multicolumn{2}{|c|}{$\begin{array}{l}\text { Potato-free Group } \\
\qquad \mathbf{n}=27\end{array}$} & \multicolumn{2}{|c|}{$\begin{array}{c}\begin{array}{c}\text { Non-potato-free } \\
\text { Group } \\
\mathbf{n}=\mathbf{6 1}\end{array} \\
\end{array}$} \\
\hline & Number & Per cent & Number & Per cent \\
\hline$\underset{<25}{\text { Age Distribution (years) }}$ & 7 & $25 \cdot 9$ & 15 & $24 \cdot 6$ \\
\hline $25-$ & 12 & $44 \cdot 4$ & 22 & $36 \cdot 1$ \\
\hline \multirow[t]{2}{*}{$30+$} & 8 & $29 \cdot 6$ & 24 & $39 \cdot 3$ \\
\hline & \multicolumn{4}{|c|}{$x^{2}=0.84 ; D F=2 ; 0.70>P>0.50$} \\
\hline \multirow[t]{4}{*}{ Social Class $_{\text {I }}$} & \multirow{3}{*}{\multicolumn{2}{|c|}{ 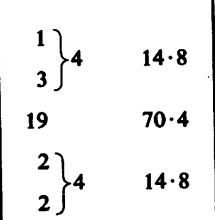 }} & $\left.\begin{array}{l}5 \\
9\end{array}\right\} 14$ & $23 \cdot 0$ \\
\hline & & & 40 & $65 \cdot 6$ \\
\hline & & & $\left.\begin{array}{l}2 \\
5\end{array}\right\} 7$ & $11 \cdot 5$ \\
\hline & \multicolumn{4}{|c|}{$x^{2}=0.84 ; D F=2 ; 0.70>P>0.50$} \\
\hline \multirow[t]{2}{*}{$\begin{array}{l}\text { Religion } \\
\text { Roman Catholic } \\
\text { Protestant }\end{array}$} & $\begin{array}{l}10 \\
17\end{array}$ & $\begin{array}{l}37 \cdot 0 \\
63 \cdot 0\end{array}$ & $\begin{array}{l}27 \\
34\end{array}$ & $\begin{array}{l}44 \cdot 3 \\
55 \cdot 7\end{array}$ \\
\hline & \multicolumn{4}{|c|}{$x^{2}=0.16 ; D F=1 ; 0.70>P>0.50$} \\
\hline
\end{tabular}

\section{RESULTS}

The maternal age distribution, social class, and religion in the potato-free and in the non-potato-free? groups are shown in Table I. None of the com $\Rightarrow$ parisons of these factors between the groups was? significant at $P<0.05$ used throughout. Similarly when the number of pregnancies, normal living. children, and abortions (Table IIA) was examine in the two groups, comparisons were not significanto However, as the numbers were small, groupings hac to be employed and the analyses were capable of detecting only large differences between the groups:Some differences were, in fact, quite large. Fow example, in the potato-free group $7.4 \%$ had has two or more normal living children, whereas in the non-potato-free group this figure was $26 \cdot 2 \%$ (Table IIA). Again, when the number of abortions in the

TABLE IIA

OUTCOME OF PREVIOUS PREGNANCIES IN POTATO-FREE AND NON-POTATO-FREE GROUPS

\begin{tabular}{|c|c|c|c|c|}
\hline \multirow{2}{*}{$\begin{array}{l}\text { Outcome of Previous } \\
\text { Pregnancies }\end{array}$} & \multicolumn{2}{|c|}{ Potato-free Group } & \multicolumn{2}{|c|}{$\begin{array}{c}\text { Non-potato-free } \\
\text { Group }\end{array}$} \\
\hline & Number & Per cent & Number & Per द्gnt \\
\hline Number $_{1}$ & 10 & $37 \cdot 0$ & 14 & $23 \overline{0}$ \\
\hline 2 & 8 & $29 \cdot 6$ & 17 & $27 \cdot 9$ \\
\hline 3 & 6 & $22 \cdot 2$ & 16 & $26 \cdot 2$ \\
\hline 4 & $1)$ & & 67 & \\
\hline 5 & 1 & & 5 & \\
\hline 6 & -3 & $11 \cdot 1$ & -114 & $23 \cdot 0 \rightleftharpoons$ \\
\hline 7 & 1 & & 1 & \\
\hline \multirow[t]{2}{*}{8} & $-J$ & & $2\}$ & \\
\hline & \multicolumn{4}{|c|}{$x^{2}=2 \cdot 82 ; \mathrm{DF}=3 ; 0 \cdot 50>\mathrm{P}>0.30$} \\
\hline \multirow[t]{6}{*}{$\begin{array}{c}\text { Living Normal } \\
0\end{array}$} & 16 & $59 \cdot 3$ & 31 & \\
\hline & 9 & $33 \cdot 3$ & 14 & $23 \cdot 0 \cong$ \\
\hline & -1 & & 97 & \\
\hline & $1\} 2$ & $7 \cdot 4$ & $3\} 16$ & $26 \cdot 2$ \\
\hline & $1]$ & & 4] & \\
\hline & \multicolumn{4}{|c|}{$x^{2}=4 \cdot 12 ; D F=2 ; 0.20>P>0.100$} \\
\hline \multirow[t]{5}{*}{$\begin{array}{r}\text { Abortions } \\
0\end{array}$} & 19 & $70 \cdot 4$ & 34 & 55 \\
\hline & $7\}_{8}$ & $29 \cdot 6$ & 197 & \\
\hline & $1 \int^{0}$ & & $7\} 27$ & $44 \cdot 3 \frac{0}{\frac{1}{C}}$ \\
\hline & - & & 1) & \\
\hline & \multicolumn{4}{|c|}{$x^{2}=1 \cdot 12 ; \mathrm{DF}=1 ; 0.30>P>0.20$} \\
\hline
\end{tabular}


TABLE IIB

PREVIOUS PREGNANCIES IN POTATO-FREE AND NON-POTATO-FREE GROUPS WHICH LED TO AN INFANT WITH ASB

\begin{tabular}{|c|c|c|c|c|}
\hline \multirow{2}{*}{$\begin{array}{l}\text { Previous } \\
\text { Pregnancies } \\
\text { ending in }\end{array}$} & \multicolumn{2}{|c|}{ Potato-free Group } & \multicolumn{2}{|c|}{$\begin{array}{c}\text { Non-potato-free } \\
\text { Group }\end{array}$} \\
\hline & Number & Per cent & Number & Per cent \\
\hline \multicolumn{5}{|l|}{ ASB } \\
\hline $\mathbf{0}$ & - & - & - & - \\
\hline 1 & 22 & $81 \cdot 5$ & 54 & $88 \cdot 5$ \\
\hline 2 & 4 & $14 \cdot 8$ & 7 & $11 \cdot 5$ \\
\hline \multirow[t]{2}{*}{3} & 1 & $3 \cdot 7$ & 一 & - \\
\hline & \multicolumn{4}{|c|}{ Exact probability $=0.33$} \\
\hline \multicolumn{5}{|l|}{ Anencephaly } \\
\hline \multirow{4}{*}{$\begin{array}{l}0 \\
1 \\
2\end{array}$} & 20 & $74 \cdot 1$ & 40 & $65 \cdot 6$ \\
\hline & $4\}_{7}$ & 25.0 & $\left.{ }^{19}\right\}_{21}$ & 34.4 \\
\hline & $3 \int^{1}$ & & $2 \int^{2-}$ & \\
\hline & \multicolumn{4}{|c|}{$x^{2}=0.29 ; D F=1 ; 0.70>P>0.50$} \\
\hline \multicolumn{5}{|l|}{ Spina bifida } \\
\hline $\mathbf{0}$ & 7 & $25 \cdot 9$ & 18 & $29 \cdot 5$ \\
\hline 1 & $18)$ & & $41)$ & \\
\hline 2 & $1\} 20$ & $74 \cdot 1$ & $2 \int$ & 8 \\
\hline \multirow[t]{2}{*}{3} & $1]$ & - & - & - \\
\hline & \multicolumn{4}{|c|}{$x^{2}=0.008 ; D F=1 ; 0.95>P>0.90$} \\
\hline
\end{tabular}

Brackets indicate groupings for $\chi^{2}$

potato-free and non-potato-free groups was considered a substantial difference was noted: $29 \cdot 6 \%$ and $44 \cdot 3 \%$ respectively (Table IIA).

Table IIb shows previous pregnancies which resulted in an infant with ASB. There was no significant difference between the two groups (exact $\mathbf{P}=\mathbf{0 . 3 3}$ ). In the potato-free and non-potato-free groups $18.5 \%$ and $11.5 \%$ respectively had had two or more infants with ASB. When anencephaly and spina bifida in previous pregnancies were considered separately (Table IIB) again, none of the comparisons was significant at $\mathbf{P}<0.05$. With the above reservations, it appeared that the two groups were reasonably comparable with the factors recorded.

The outcome of the current pregnancies for the two groups is shown in Table III. In the potato-free group, of 23 of the 27 pregnancies which went to term two were male infants with anencephaly, 22 normal infants were born, one pregnancy led to normal twins, and four pregnancies ended in spontaneous abortions; none, however, was examined
TABLE III

OUTCOME OF THE CURRENT PREGNANCY IN THE POTATO-FREE AND NON-POTATO-FREE GROUPS

\begin{tabular}{l|c|c|c}
\hline & \multicolumn{3}{|c}{ Result of Pregnancy } \\
\cline { 2 - 4 } & Abortion & $\begin{array}{c}\text { Normal } \\
\text { Live Born }\end{array}$ & $\begin{array}{c}\text { Infant with } \\
\text { ASB }\end{array}$ \\
\hline $\begin{array}{c}\text { Potato-free group } \\
(n=27) \\
\begin{array}{c}\text { Non-potato-free group } \\
(n=61)\end{array}\end{array}$ & 4 & $22 \dagger$ & 2 \\
\hline
\end{tabular}

*One abortion at 17 weeks revealed fetus with inencephaly †Included a twin pregnancy

pathologically. In the non-potato-free group of 56 pregnancies which went to term, two led to infants with spina bifida. In this group 55 normal children were born; one pregnancy led to normal twins. Five pregnancies ended in spontaneous abortions; the only fetus examined had inencephaly. The incidence of ASB in the potato-free group (8.7\%) and in the non-potato-free group (3.6\%) showed no significant difference $(P=0 \cdot 58)$.

\section{Discussion}

In 1972 Renwick postulated that exposure to blight-affected potatoes during early pregnancy was associated with ASB. The hypothesis was based on data which demonstrated a strong correlation between the geographical distribution of ASB and the blight score. He further suggested that $95 \%$ of ASB occurrences could be prevented by avoidance of potatoes during early pregnancy. In more recent studies of the prevalence from year to year of ASB and potato blight, negative findings were obtained (Emanuel, 1972; MacMahon, Yen, and Rothman, 1973; Spiers, 1973; Field and Kerr, 1973; Kinlen and Hewitt, 1973). However, the hypothesis may be directly tested, either by animal experiments or by a trial of potato avoidance.

Poswillo et al., (1972) fed female marmosets with blighted potato concentrates from Kerr Pink tubers naturally infested with Phytophthora infestans and found a cranial malformation in four of 11 embryos. The malformation involved the occipital region, consisting of an osseous defect with replacement of bone by collagenous membrane and a distortion of the underlying brain. Supplementary experiments in which the concentrates of normal potatoes, tubers rejected by graders in the food industry, and potatoes infected with Erwinia carotovora were fed to pregnant marmosets failed to produce any gross abnormalities in the embryos (Poswillo et al., 1973). 
Caution is always necessary in applying animal experiments to man, and a critical evaluation of the hypothesis can be made only by a trial of potato avoidance. A recent study by Clarke, McKendrick, and Sheppard (1973), based on 83 Liverpool schoolchildren with spina bifida, found no significant differences in the amounts of potato eaten by their mothers compared with matched controls. Several reports have also indicated that the avoidance of potatoes in early pregnancy does not prevent the recurrence of ASB. Lorber et al., (1973) described a mother with a child with a meningomyelocele, whose next pregnancy resulted in an infant with anencephaly and spina bifida, in spite of potato avoidance six months before conception and throughout pregnancy. More recently of nine pregnancies in women who had avoided potatoes before and throughout pregnancy, six resulted in the birth of a normal infant, one in an 18-week spontaneous abortion, one in an infant with spina bifida and hydrocephalus, and the other in an infant with anencephaly and spina bifida (Lorber, 1974).

Although in the present study the number of patients is small and allocation to the groups is non-random, it fails to support Renwick's hypothesis that potato avoidance before conception and throughout pregnancy alters the risk of having an infant with ASB. The risk of ASB, when there is already an affected sib, is several times greater than that for the general population. In Britain this risk among live- and still-births averages about $5 \%$ (Williamson, 1965; Carter et al., 1967) and rises to $10 \%$ after a second ASB sib (Carter and Roberts, 1967). In the present study, in the potato-free group, two of the 23 pregnancies at term $(8 \cdot 7 \%)$ were ASB infants, whereas in the non-potato-free group, two of 56 pregnancies at term $(3.6 \%)$ were ASB infants. Clearly, the avoidance of potatoes failed to reduce the recurrence of ASB.

Failure of short-term avoidance of potatoes may be explained by storage of the teratogen either in the liver or in fat of the mother with a gradual release over several months or even years (Renwick, Possamai, and Munday, 1974). Until the specific teratogen(s) has been identified, such a hypothesis is difficult to test. The genotype of the fetus has an important role in the development of ASB. In animals it has been observed that not only different species but also different strains react differently to similar teratogens (Fraser and Fainstat, 1951; Runner, 1959). Whatever the environmental factors may be in the causation of ASB, it is probably only fetuses which are genetically susceptible that are at risk. It is this which makes the investigation of aetiological factors in ASB difficult.
We are most grateful to the obstetricians, record officers, and general practitioners for access to families, and we are indebted to the patients for their co-operation.

This work was supported by a grant from the Northern Ireland Association for Spina Bifida and Hydrocephalus.

Requests for reprints: Professor N. C. Nevin, Department of Medical Genetics, Institute of Clinical Science, Grosvenor Road, Belfast BT12 6BJ, Northern Ireland.

\section{REFERENCES}

Carter, C. O., Laurence, K. M., and David, P. A. $\stackrel{\vec{\circ}}{\vec{*}}$ (1967). The genetics of the major central nervous $\vec{\omega}$ system malformations based on the South Wales socio-genetic investigation. Develop. Med. Child $\widetilde{\Phi}$ Neurol., 9, Supp. 13, p. 30. and RoBerTS, J. A. F. (1967). The risk of recurrence after two children with central-nervous-system mal-? formations. Lancet, 1, 306.

Clarke, C. A., McKendrick, O. M., and Sheppard, P. M. (1973). Spina bifida and potatoes. Brit. med. $J$, 3, 251.

Elwood, J. H. and Nevin, N. C. (1973). Factors associ- $\bar{\emptyset}$ ated with anencephalus and spina bifida in Belfast. Brit. J. prev. soc. Med., 27, 73.

EMANUEL, I. (1972). Non-tuberous neural-tube defect Lancet, 2, 879.

FEDRICK, J. (1974). Anencephalus and maternal tea drinking: Evidence for a possible association. Procol roy. Soc. Med., 67, 356.

FIELD, B. and KeRR, C. (1973). Potato blight and neural tube defects. Lancet, 2, 507.

Fraser, F. C. and Fainstat, T. D. (1951). Production of congenital defects in offspring of pregnant mice्ड treated with cortisone. Pediatrics, 8, 527.

KinLen, L. and HewitT, A. (1973). Potato blight and anencephalus in Scotland. Brit. J. prev. soc. Med. 27, 208.

KNox, E. G. (1972). Anencephalus and dietary intakes Brit. J. prev. soc. Med., 26, 219.

LECK, I. (1974). Causation of neural-tube defects: Clues from epidemiology. Brit. med. Bull, 30, 158.

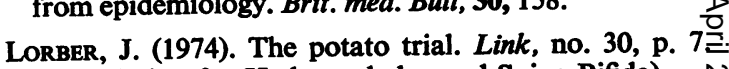
(Association for Hydrocephalus and Spina Bifida). N

, Stewart, C. R., and Ward, A. M. (1973). Alpha fetoprotein in antenatal diagnosis of anencephaly anф spina bifida. Lancet, 1, 1187.

MacMahon, B., Yen, S., and Rothman, K. J. (1973)? Potato blight and neural-tube defects. Lancet, 1, 598

Poswillo, D. E., SOPHER, D., and MrTChell, S. (1972) Experimental induction of foetal malformation witho 'blighted' potato: a preliminary report. Nature (Lond.), 239, 462. 
Coxon, D. T., Curtis, R. F., and PrICE, K. R. (1973). Investigations into the teratogenic potential of imperfect potatoes. Teratology, 8, 339.

ReNwick, J. H. (1972). Hypothesis: Anencephaly and spina bifida are usually preventable by avoidance of a specific but unidentified substance present in certain potato tubers. Brit. J. prev. soc. Med., 26, 67.

(1973). Potatoes and neural-tube defects. Lancet, 2,562 .
Possamai, A. M., and Munday, M. R. (1974). Potatoes and spina bifida. Proc. roy. Soc. Med., 67, 360.

RUNNER, M. N. (1959). Inheritance of susceptibility to congential deformity. Metabolic clues provided by experiments with teratogenic agents. Pediatrics, 23, 245.

SPIERS, P. S. (1973). Spina bifida, anencephaly, and potato blight. Lancet, 1, 426.

Williamson, E. M. (1965). Incidence and family aggregation of major congenital malformations of central nervous system. J. med. Genet., 2, 161. 